\title{
O TURNAROUND DA EMPRESA COM FOCO EM RECURSOS E CAPACIDADES: UM ESTUDO DE CASO NO NEGÓCIO DE ALIMENTOS
}

\section{RESUMO}

O objetivo deste artigo é mostrar o que ocorre com os recursos e capacidades estratégicos envolvidos em um processo de turnaround visando à criação de valor para os clientes da empresa, sob a perspectiva da Visão Baseada em Recursos - VBR. Foi adotado o método de pesquisa qualitativo de caráter exploratório descritivo para o estudo de caso de uma empresa que é uma das principais multinacionais que operam globalmente no mercado de ingredientes para indústria de alimentos, atuando no segmento empresa-empresa. Foram entrevistados oito executivos da área de vendas, marketing, pesquisa e desenvolvimento, precificação e lucratividade e de cadeia de suprimentos que atuavam na empresa na época em que ocorreu o turnaround, com a aplicação de um roteiro padronizado com perguntas abertas. Os dados foram tratados com a utilização da Análise de Conteúdo. Foi constatado que a dificuldade para perceber as mudanças do mercado ocasionadas pelo aumento da concorrência e dos custos dos produtos, e o desconhecimento das necessidades dos clientes, se destacaram como as causas do declínio, ambas atribuídas à deficiência da gestão da empresa em antever e adaptar as estratégias às mudanças do cenário externo. $\mathrm{O}$ início do turnaround se deu com mudanças na equipe de liderança da empresa que provocou a revisão das estratégias que possibilitaram a retomada da vantagem competitiva. Os resultados da pesquisa indicam que os recursos, equipe comercial e conhecimento técnico, e as capacidades, mudança de mindset e sinergia entre as áreas da empresa, foram decisivos para o sucesso das estratégias adotadas.

Palavras-chave: Indústria Alimentícia; Declínio; Turnaround; Criação de Valor; Visão Baseada em Recursos.

\section{THE TURNAROUND OF THE COMPANY WITH A FOCUS ON RESOURCES AND CAPABILITIES: A}

\section{CASE STUDY IN THE FOOD BUSINESS}

\begin{abstract}
The purpose of this article is to show what happens to the resources and strategic capabilities involved in a turnaround process aiming at creating value for the company's customers from the perspective of the Resource Based View - RBV. We adopted the qualitative research method of exploratory descriptive character for the case study of a company that is one of the main multinationals that operate globally in the ingredients market for food industry, working in the business-to-business segment. Eight executives from the sales, marketing, research and development, pricing and profitability and supply chain areas that worked at the company were interviewed at the time of the turnaround, with the application of a standardized script with open questions. The data were treated with the use of Content Analysis. It was found that the difficulty of perceiving the changes in the market caused by increased competition and product costs and the lack of knowledge of customer needs were highlighted as the causes of the decline, both attributed to the deficiency of the company's management in anticipating and adapting the strategies to changes in the external scenario. The turnaround began with changes in the company's leadership team, which led to the review of the strategies that allowed the resumption of competitive advantage. The results of the research indicate that the resources, commercial team and technical knowledge, and the capabilities, mindset change and synergy between the company's areas were decisive for the success of the strategies adopted.
\end{abstract}

Keywords: Food Industry; Decline; Turnaround; Value Creation; Resource-Based View. 


\section{EL TURNAROUND DE LA EMPRESA CON FOCO EN RECURSOS Y CAPACIDADES: UN ESTUDIO DE CASO EN EL NEGOCIO DE ALIMENTOS}

\section{RESUMEN}

El objetivo de este artículo es mostrar lo que ocurre con los recursos y capacidades estratégicas involucrados en un proceso de turnaround para la creación de valor para los clientes de la empresa, desde la perspectiva de la Visión Basada en Recursos - VBR. Se adoptó el método de investigación cualitativo de carácter exploratorio descriptivo para el estudio de caso de una empresa que es una de las principales multinacionales que operan globalmente en el mercado de ingredientes para la industria de alimentos, actuando en el segmento empresa-empresa. Se entrevistó a ocho ejecutivos del área de ventas, marketing, investigación y desarrollo, precificación y rentabilidad y de cadena de suministros que actuaban en la empresa en la época en que ocurrió el turnaround, con la aplicación de un itinerario estandarizado con preguntas abiertas. Los datos fueron tratados con el uso del análisis de contenido. Se constató que la dificultad para percibir los cambios del mercado ocasionados por el aumento de la competencia y de los costos de los productos, y el desconocimiento de las necesidades de los clientes, se destacaron como las causas del declive, ambas atribuidas a la deficiencia de la gestión de la empresa en previsión y adaptación las estrategias a los cambios del escenario externo. El inicio del turnaround se dio con cambios en el equipo de liderazgo de la empresa que provocó la revisión de las estrategias que posibilitar la reanudación de la ventaja competitiva. Los resultados de la investigación indican que los recursos, equipo comercial y conocimiento técnico, y las capacidades, cambio de mindset y sinergia entre las áreas de la empresa, fueron decisivos para el éxito de las estrategias adoptadas.

Palabras clave: Industria Alimentaria; Declinación; Turnaround; Creación de Valor; Visión Basada en Recursos.

\footnotetext{
1 Mestre em Administração de Empresas pela Universidade Presbiteriana Mackenzie. Brasil. E-mail: carlosvinnicius@hotmail.com

${ }^{2}$ Doutor em Administração pela Universidade de São Paulo - USP. Professor da Universidade Presbiteriana Mackenzie. Brasil. E-mail: reynaldo.marcondes@ mackenzie.br
} 


\section{INTRODUÇÃO}

A perda de desempenho ou competitividade frente aos concorrentes é ameaça que nem sempre as empresas conseguem neutralizar de maneira eficiente, resultando no declínio organizacional. Esse fato é apontado por Carvalho (2013) que afirma que as organizações encontram dificuldades em perceber as mudanças ambientais que interferem na sua rotina, tornando-se incapazes de lidar com os problemas. O estudo de Torres et al. (2008) chama atenção para a perda de competitividade e o aumento dos casos de declínio e mortalidade de empresas brasileiras, situação que tende a se agravar à medida que o ambiente se torna mais dinâmico.

Empresas reagem de maneiras distintas a mudanças ambientais, sendo que esta reação, quando positiva, resulta de estratégias eficazes que, muitas vezes, as deixam mais fortes. Para Serra, Ferreira e Contrigiane (2009), ainda há muito a ser explorado em relação à capacidade das empresas em recuperarem o desempenho ou competitividade, fenômeno conhecido na literatura como turnaround. De acordo com Santos (2006), o turnaround se evidencia por uma recuperação bem sucedida do desempenho da empresa após uma fase de declínio.

Esses autores apontam a importância de se identificar os recursos fundamentais como base da estratégia para o turnaround. A utilização produtiva dos recursos que resulta nas estratégias implementadas é crucial para explicar o desempenho empresarial (Santos, 2006).

Purves et al. (2016) defendem que há muito pouca pesquisa realizada com foco em fatores não financeiros, que são impactantes no sucesso do turnaround, especialmente nas suas estratégias e no ambiente interno da empresa.

Por envolver recursos, a pesquisa objeto deste artigo adotou a abordagem da Visão Baseada em Recursos (VBR) que se destaca como uma das teorias mais profícuas dentro da Administração Estratégica (Pinto et al., 2016). Volta-se para a eficiência e eficácia das organizações por meio da exploração dos seus recursos e capacidades para obter a vantagem competitiva (Grant, 2001, Barney \& Hesterly, 2011).

Segundo os autores da VBR, as empresas analisam o ambiente externo e adaptam suas estratégias através dos seus recursos e capacidades estratégicos. Eles defendem que as organizações criam mais valor para os clientes em relação aos concorrentes, quando os recursos e capacidades são valiosos e dificies de serem replicados pelos concorrentes (Peteraf \& Barney, 2003, Barney \& Clark, 2007). Os recursos são ativos tangíveis e intangíveis que uma empresa controla e utiliza para criar e implementar estratégias (Barney \& Clark, 2007), enquanto capacidades são as habilidades de integrar recursos organizacionais com o objetivo de atingir um determinado resultado (Helfat \& Peteraf, 2003).

A VBR traz relevante contribuição na compreensão dos recursos e capacidades, que aliados às estratégias definidas com base na avaliação das mudanças no ambiente, são determinantes para frear situações de declínio, permitir a sobrevivência das empresas, assim como, recuperar níveis desejados de desempenho (Santos, 2006).

A VBR tem sido criticada por alguns autores por não contemplar um maior dinamismo no seu modelo de análise de recursos e capacidades que levam à criação de valor superior e, consequentemente, à vantagem competitiva. Dessa maneira, ao se considerar o turnaround como um evento ocorrido em um ambiente que sofreu uma transformação repentina, entende-se que possa trazer uma contribuição para ampliar o entendimento da VBR em situações além daquela em que suas bases foram desenvolvidas originalmente.

A pesquisa foi desenvolvida utilizando-se um caso de empresa que inesperadamente entrou em declínio de lucratividade pela redução do retorno sobre vendas (ROS - Return On Sales), entre os anos de 2009 e 2011. Foi uma surpresa, pois esse período foi um momento econômico positivo para a indústria de ingredientes alimentícios no Brasil, onde a empresa atua. Isso se deveu à crise econômica nos EUA em 2008 e na Europa Ocidental em 2011, que provocou um redirecionamento dos investimentos estrangeiros para países emergentes. O cenário positivo favoreceu vários segmentos da economia no Brasil. Apesar do mercado de ingredientes seguir em crescimento, a empresa do estudo, que apresentava um histórico de lucratividade positiva em torno de $3 \%$ de ROS até o ano de 2008, apresentou queda nos três anos seguintes, chegando à lucratividade negativa de $9 \%$ em 2011, a mais baixa de sua história.

Essa queda foi atribuída ao aumento dos custos da cadeia de suprimentos, agravado pelo aumento expressivo de competitividade desse mercado, uma vez que concorrentes multinacionais foram atraídos para ele, e os nacionais fortaleceram suas estruturas para aproveitar o momento positivo do mercado brasileiro.

A empresa do estudo é uma multinacional centenária, uma das líderes globais e nacionais do mercado de ingredientes, com atuação em todos os continentes. É destacada no mercado em função da imagem de tradição, qualidade dos produtos e do serviço associado à venda dos seus produtos.

Pelo fato em si, provocou a necessidade de reação e adequação imediata à nova realidade do mercado para frear a tendência de queda e iniciar rapidamente a recuperação, ou seja, um turnaround. Como consequência, não apenas foi retomada a lucratividade anterior, como esta foi superada nos tres anos seguintes, atingindo o patamar de 5\% em 2014. 
Para tanto, foram feitas mudanças, entre elas, a substituição da liderança da empresa, alterações nas estratégias operacionais e de mercado, adotadas simultaneamente de maneira que a empresa pudesse atender rapidamente às novas necessidades do mercado e recuperar a sua lucratividade.

Diante desse cenário, a indagação natural foi sobre o que teria acontecido com os recursos e capacidades da empresa para que o turnaround resultasse positivo.

Para responder essa questão foi definido como objetivo geral, destacar os recursos e capacidades que se mostraram estratégicos no processo de turnaround tendo em vista a criação de valor para os clientes da empresa. Para tanto, buscou-se: a) entender os antecedentes do declínio do negócio; b) descrever as estratégias envolvidas no turnaround; e c) caracterizar os recursos e capacidades que se tornaram estratégicos no suporte às estratégias do turnaround.

\section{REFERENCIAL TEÓRICO}

Esta seção inicia-se com um apanhado teórico acerca das causas do declínio organizacional, e em seguida trata as estratégias de turnaround. $\mathrm{Na}$ sequencia, trata dos conceitos de vantagem competitiva e criação de valor, faz um apanhado teórico sobre recursos e capacidades como base das estratégias, finalizando com o VRIO, uma ferramenta para identificação dos recursos e capacidades que possibilitam a criação de valor e vantagem competitiva sustentável, ou seja, aqueles tidos como estratégicos.

\subsection{Conceituação de Declínio e Turnaround}

Segundo Weitzel e Jonsson (1989) e Santos (2006), o declínio se caracteriza pela etapa do ciclo de vida da empresa em que ela falha em antecipar, reconhecer, evitar, neutralizar, ou adaptar, ameaças internas e externas à sobrevivência no longo prazo, trazendo resultados opostos aos desejados, como a queda no crescimento de vendas ou lucratividade.

Bibeault (1999) e Slatter e Lovett (2009) defendem que as causas do declínio se dividem em internas e externas à empresa, sendo que as causas externas estão relacionas com a falha da empresa em identificar as mudanças das exigências do mercado ou dos clientes por alterações sociais ou por ação dos concorrentes. As causas internas, em grande parte se devem a ineficiência da gestão ou alguma causa derivada desta, agravada ainda por outros fatores comportamentais da equipe. (Bibeault, 1999, Santos, 2006, Slatter \& Lovett, 2009).

Para Purves et al. (2016) uma equipe bem integrada é uma das condições essenciais para proteger a empresa de declínio e falência. Em estudo realizado na Austrália, esses autores identificaram que nas empresas que sofreram declínio, as equipes de executivos não tinham desenvolvido a capacidade de reconhecer a situação de crise em que se encontravam. Com isso, mantiveram-se na inércia das decisões o que levou ao não aproveitamento de oportunidades, bem como ao não ajuste do seu plano estratégico de negócios. A gestão não produtiva de um recurso estratégico é indicada como uma das causas da inercia em antecipar as ameaças, dificultando operacionalizar uma resposta eficaz. (Weitzei \& Jonsson, 1989, Torres et al., 2013).

Segundo Santos (2006) há uma forte relação entre os recursos e capacidades da empresa e a situação de declínio e recuperação, de maneira que há sempre oportunidades de recuperação, desde que foque naqueles estratégicos que fazem a diferença no ambiente externo.

\subsubsection{Turnaround}

Bibeault (1999), um autor pioneiro na análise do processo de turnaround entende ser este constituído de várias etapas, que se inicia quando a empresa ainda está em declínio. Esse autor defende a mudança de gestão como uma etapa inicial e crítica em função das transformações necessárias que são motivadas por esta etapa, corroborando as posições de Schendel et al. (1976), Hofer (1980), Thiétart (1988) e Slatter e Lovett (2009).

As fases do turnaround estão contidas em duas etapas: o encolhimento - retrenchment - e a recuperação, frente aos objetivos básicos da empresa de sobrevivência e lucratividade, segundo Robbins e Pearce (1992) e Serra et al., (2009).

O encolhimento, também chamado de downsizing ou downscoping (Bibeault, 1999, Robbins \& Pearce, 1992) é uma resposta da empresa a uma instabilidade do ambiente externo, que consiste em ações de redução de custos e/ou redução de ativos visando minimizar as causas do declínio e evitar a falência. Segundo estes autores, ações de redução de custo e foco nos negócios prioritários são atividades indispensáveis que se estendem às atividades características das estratégias de recuperação para restabelecer a lucratividade em situações de declínio.

Quando a empresa consegue controlar ou sessar o declínio ela precisa definir a estratégia de recuperação a ser adotada com base nas causas do declínio, para que volte aos patamares de desempenho anteriores. (Bibeault, 1999).

\subsubsection{Estratégias de turnaround}

As estratégias de turnaround são compostas de algumas etapas ou ações específicas, começando pela estabilização da crise por meio do controle de caixa, redução de estoques e despesas não essenciais. (Slatter \& Lovett, 2009). Quanto à mudança da liderança é defendida por Schendel et al. (1976), Hofer 
(1980), Thiétart (1988) e Bibeault (1999) pelo fato da gestão ser apontada como a principal causa do declínio.

As ações de turnaround podem ser divididas em operacionais, aquelas focadas na performance de curto prazo, e em estratégicas, as que focam no longo prazo. (Hofer, 1980). Hambrick e Schecter (1983) chamam as operacionais de estratégias de eficiência, e as ações estratégicas, de empreendedoras. Essas últimas são voltadas ao aumento de receita, ao reenfoque do produto no mercado, à ênfase em segmentos ou aos nichos mais lucrativos.

Segundo Hofer (1980) as estratégias de aumento de receita consistem em ações de incentivos para fortalecer as vendas, redução de preços e aumento de ações de marketing, enquanto as estratégias de redução de custo focam em cortes de despesas fixas, mão de obra e despesas não essenciais, e produzem resultados mais rápidos que a de aumento de receita.

Já as ações de turnaround estratégicas ou empreendedoras, visam a resultados de longo prazo, como crescimento em vendas e aumento de participação de mercado por meio da atuação do marketing, lançamento de novos produtos, redução de preços, reforço da estrutura de vendas, ou reposicionamento do binômio produto-mercado com o objetivo em atuar em segmentos mais lucrativos. (Hambrick \& Schecter, 1983, Robins \& Pearce, 1992).

As ações estratégicas ou empreendedoras dependem da posse de instrumentos estratégicos que possibilitem a avaliação eficaz do ambiente externo, das necessidades dos clientes, das forças dos concorrentes, dos recursos internos que permitem o desenvolvimento de produtos superiores e consequente destaque em relação aos concorrentes. (Hofer, 1980, Hambrick \& Schecter, 1983).

Slatter e Lovett (2009) defendem que é preciso identificar rapidamente as unidades de negócios e os segmentos críticos de produtos e clientes com fraco desempenho, e os que têm potencial de geração de lucro no curto e longo prazo. Nesse sentido Serra et al. (2009) defendem que é preciso determinar os segmentos de produto e mercado, e as atividades que estão em conformidade com os recursos disponíveis e com o ambiente externo. Como critério de escolha, estaria a atratividade do segmento baseada na análise do mercado em relação à vantagem competitiva que a empresa pode obter.

O sucesso do turnaround, de acordo com Tangpong et al. (2015), pode ser obtido com a implementação de ações logo no início do processo de declínio, tais como, a saída de mercados e desinvestimentos. Portanto, o timing dessas decisões estratégicas é um fator de grande relevância.

\subsection{Vantagem Competitiva, Capacidades e Criação de Valor}

Barney (1991) afirma que uma empresa possui vantagem competitiva quando é capaz de implementar estratégias que criam maior valor econômico do que as empresas rivais, ou seja, suas estratégias se destacam em relação àquelas dos concorrentes.

Sendo a vantagem competitiva obtida com base em recursos únicos, heterogêneos e inacessíveis aos concorrentes (Barney, 1991), caso esses recursos permaneçam únicos e difíceis de serem reproduzidos ao longo o tempo, a vantagem competitiva se torna sustentável. (Kretzer \& Menezes, 2006).

Peteraf e Barney (2003) apresentam o conceito de valor como a diferença entre o benefício percebido, ou preço que o cliente estaria disposto a pagar, e o custo econômico, enquanto Christopher (2003) acrescenta que o valor é criado quando os benefícios de uma transação percebidos pelo cliente, superam os custos totais. Segundo Kretzer e Menezes (2006) sustentar a vantagem sobre o concorrente está diretamente relacionando a manutenção de valor para o cliente.

O cliente não compra produtos, mas sim benefícios e, por isso, destaca a importância do conhecimento do que o cliente valoriza e dos processos para fornecer valor como um requisito básico para conquista e manutenção do cliente, e consequentemente a obtenção de vantagem competitiva. (Christopher, 2003).

Conforme Sinchi-Levi, Kaminsky e Sinchi-Levi (2007) o serviço com valor agregado é um importante recurso no cenário competitivo que tem forte relação com os esforços de diferenciação para evitar a competição baseada em preço, a baixa rentabilidade e a redução da vantagem competitiva, muito evidente no segmento B2B, onde o cliente é sensível ao serviço. (Christopher, 2003).

Os serviços e suporte técnico buscam agregar o máximo de valor aos produtos, resultando na aproximação do cliente para melhorar a percepção do atendimento, satisfazendo as suas necessidades e trazendo novas oportunidades. O relacionamento é outra importante dimensão de valor, que tem a ver com a conexão que a empresa consegue estabelecer com o cliente ao longo do tempo. Isso dificulta a sua substituição como fornecedor por um concorrente, e facilita o conhecimento das necessidades do cliente. (Sinchi-Levi et al., 2007).

\subsubsection{Recursos e Capacidades}

O entendimento da necessidade do cliente é o elemento crucial para que a empresa identifique os recursos internos que compõem a estratégia para criar valor para ele. (Zubac, Hubbard \& Johnson, 2010).

Segundo Sirmon, Hitt e Ireland (2007), para que a empresa consiga criar valor para os clientes e para os acionistas é preciso que haja o gerenciamento de recursos, que consiste na estruturação do portfolio de recursos, seu agrupamento para construção de capacidades que permitam que o valor seja criado. 
É importante o entendimento dos recursos e capacidades por estarem diretamente relacionados com a formulação das estratégias das empresas que buscam reverter uma situação de declínio e recuperar o desempenho organizacional. (Santos, 2006).

Recursos são todos os ativos, processos organizacionais, atributos da firma, informação, conhecimento e demais forças que a empresa controla e utiliza para formular suas estratégias para melhorar a sua eficiência e efetividade. (Wernerfelt, 1984, Barney, 1991). Os recursos como insumos produtivos podem ser tangíveis e intangíveis. (Wernerfelt, 1984, Barney, 1991).

Os recursos tangíveis são os ativos quantificáveis da organização, como fábricas, equipamentos, produtos, entre outros (Barney \& Hesterly, 2011). Já os recursos intangíveis são ativos ou habilidades conquistadas pela empresa ao longo do tempo (Hall, 1992), difíceis de serem interpretados e caracterizados, como por exemplo a reputação, knowhow ou conhecimento dos funcionários, capacitações gerenciais, cultura e rotinas organizacionais, marca, identidade visual, segredos organizacionais, capacidade de inovar e processos internos (Kristandl \& Bontis, 2007).

Grant (2001) destaca a diferença entre recursos e capacidades, afirmando que recursos são itens unitários, enquanto capacidades são conjuntos de recursos realizando alguma atividade produtiva. Por outro lado, Helfat e Peteraf (2003) conceituam capacidades organizacionais como sendo a habilidade da organização para realizar um conjunto de tarefas coordenadas utilizando os recursos que disponibiliza, com objetivo de atingir um resultado final em particular. Criar capacidades envolve uma complexa combinação e coordenação de pessoas e outros recursos (Grant, 2001), sendo estas muito mais que a junção simples de recursos.

Segundo Wernerfelt (1984) as empresas criam situações para que os seus recursos sustentem uma barreira que dificulte a ação dos concorrentes.

\subsubsection{VRIO}

Para identificar os recursos considerados como estratégicos para a obtenção e sustentação da vantagem competitiva, Barney (1991) desenvolveu um modelo conhecido pela sigla VRIN (valor, raridade, inimitabilidade e não substituição), como uma ferramenta para avaliar o grau de heterogeneidade e imobilidade dos recursos entre as empresas que atuam em um setor.

O modelo sofreu posteriormente uma evolução, de maneira que o atributo "não substituível" foi incorporado ao "inimitabilidade", dando lugar então ao atributo "organizacional", e com isso o modelo proposto passou a ser identificado pela sigla VRIO (valor, raridade, inimitabilidade e organização). (Barney \& Clark (2007). A aplicação deste modelo permite a avaliação do potencial de um recurso ou capacidade de serem estratégicos, tornando possível a formulação e implementação de estratégias eficazes.

$\mathrm{O}$ atributo valor se refere ao diferencial de benefícios do produto ou serviço que este cria na percepção do cliente, comparativamente ao custo de obtenção destes junto aos concorrentes. (Christopher, 2003, Peteraf \& Barney, 2003, Zubac et al., 2010). Os recursos são classificados como valiosos quando incorporados aos produtos, ajudam a explorar uma oportunidade ou neutralizar uma ameaça, gerando benefícios econômico-financeiros para a empresa. (Barney, 1991).

O atributo do recurso ou capacidade ser raro permite à empresa benefícios financeiros em relação ao seu concorrente, por meio de margens diferenciadas ou vendas acima da média. A condição de raridade está relacionada ao fato de ser mantido por um número muito pequeno de concorrentes. (Bowman \& Ambrosini, 2003, Barney \& Herterly, 2011).

A existência de valor e da raridade conferem aos recursos e capacidades a condição de gerarem a vantagem competitiva temporária, constituindo a dimensão da heterogeneidade dos recursos, um dos pilares da VBR. (Barney \& Clark, 2007).

$\mathrm{O}$ atributo da inimitabilidade de um recurso ou capacidade se refere ao grau da dificuldade de ser imitado. A dificuldade de ser imitado, contudo, não afasta a possibilidade de um competidor obter, desenvolver ou encontrar um recurso que possa substituir o recurso desejável. (Barney \& Clark, 2007).

$\mathrm{O}$ atributo da organização se refere às condições da empresa para explorar um recurso ou capacidade de maneira eficiente, por meio de processos e políticas responsáveis pelo funcionamento e integração da empresa. Dessa maneira, o que se busca é a manutenção da sua exploração contínua e permanente de maneira produtiva. (Barney \& Clark, 2007).

Sendo o recurso valioso, mas não raro, permite à empresa uma condição de paridade competitiva, ou seja, basicamente a sobrevivência no mercado. Se o recurso ou capacidade for valioso, raro, mas imitável pelos competidores, possibilita à empresa obter uma vantagem competitiva apenas temporária, podendo desfrutar as vantagens de ser um pioneiro até que um competidor replique este recurso ou encontre algum substituto. Se o recurso ou capacidade for valioso, raro, difícil de imitar, a sua exploração possibilita à empresa uma posição de vantagem competitiva sustentável. Esse modelo torna possível discutir a formulação e a implementação de estratégias, de maneira que quanto mais estratégicos forem esses atributos, maior o potencial de gerar vantagem competitiva. (Wernerfelt, 1984, Barney, 1991, Barney \& Clark, 2007, Barney \& Hesterly, 2011). 


\section{PROCEDIMENTOS METODOLÓGICOS}

\subsection{Tipo e Método de Pesquisa}

A pesquisa adotada foi a exploratória descritiva de natureza qualitativa, pois buscou o entendimento da realidade por meio de entrevistas com os executivos da empresa e observações de campo, conforme propõe Flick (2004) e Collis e Hussey (2005.

Com objetivo de entender em profundidade um fenômeno social complexo, foi adotado um estudo de caso único (Yin, 2005), feito a partir de entrevistas com protagonistas dos eventos objeto do estudo. O trabalho foi desenvolvido adotando-se o protocolo recomendado por Yin (2005), que foi determinante na estruturação desta seção.

\subsection{Apresentação do Caso}

Dada a não permissão para a divulgação do nome da empresa, como condição para a realização do estudo, estão apresentadas as suas características mais relevantes.

Trata-se de uma multinacional de grande porte que atua em todos os continentes, sendo uma das líderes mundiais e nacionais do mercado de ingredientes fornecidos à indústria de alimentos. Detém no Brasil uma participação de mercado de aproximadamente $32 \%$, enquanto o seu concorrente mais próximo detém $18 \%$. Possui um parque produtivo de elevada capacidade para o tipo de negócio, localizado na cidade de São Paulo, atendendo a mais de 250 clientes industriais, todas elas indústrias de alimentos que atuam no mercado nacional. Conforme mencionado anteriormente, a empresa entrou em declínio de lucratividade entre os anos de 2009 e 2011, sendo o ROS - Return On Sales a medida de declínio utilizada, conforme propõe Robbins e Pearce (1992).

A empresa comercializa cinco tipos de ingredientes para a formulação e a produção de alimentos. Por esse motivo, a empresa mantém relacionamentos muito próximos com os departamentos de $\mathrm{P} \& \mathrm{D}$ dos clientes, prestando serviços técnicos agregados aos produtos oferecidos.

Esses serviços permitem que os clientes praticamente terceirizem parte das formulações de novos alimentos. Isso possibilita o acesso à informações de mercado, tendências de novos produtos e hábitos de consumo, tornando a empresa também um parceiro do departamentos de marketing dos clientes.

Para oferecer esse serviço, a empresa dispõe de estrutura laboratorial de última geração, capaz de dar suporte às empresas de alimentos de todos os portes no desenvolvimento de produtos em todos os segmentos, como bebidas, panificados, confeitos, lácteos, salgados e cárneos.

A escolha desta empresa se deveu ao fato de seu porte e posicionamento como líder em um setor concorrido e ter sido repentinamente ameaçada pelos concorrentes, com efetivas perdas em seu negócio. Além disso, por ter tido facilitado o acesso aos seus executivos.

\subsection{Instrumento e Coleta dos Dados}

Foi utilizado um roteiro padronizado com oito perguntas conectadas com os objetivos específicos e o referencial teórico, constante no Apêndice A. Para a sua elaboração foi utilizado uma matriz de amarração a fim de garantir a consistência do trabalho, cujo modelo encontra-se no Apêndice A.

Foram intencionalmente entrevistados oito executivos que atuavam na empresa em cargos de liderança nas áreas comercial, $\mathrm{P} \& \mathrm{D}$, marketing e cadeia de suprimentos no período em que ocorreu o turnaround, portanto, detendo a experiência e as informações necessárias para responder adequadamente as perguntas. (Creswell, 2007). As entrevistas ocorreram nos meses de julho e agosto de 2015.

Por compromisso de confidencialidade não estão identificados os nomes dos entrevistados e seus cargos, tendo-se utilizado a seguinte referência: E1 (vendas América Latina), E2 (marketing Brasil), E3 (vendas Brasil), E4 (vendas Brasil), E5 (marketing América Latina, E6 (pesquisa e desenvolvimento Brasil), E7 (cadeia de suprimentos Brasil) e E8 (precificação / lucratividade).

\subsection{Tratamento e Análise dos Dados}

Foram aplicadas as técnicas de análise de conteúdo no tratamento e na análise dos dados, de acordo com Bardin (2000), compreendendo as etapas de pré-análise, exploração do material, o tratamento e a análise dos dados.

A pré-análise consistiu na organização das respostas de maneira que cada uma delas ficasse aderente à pergunta, pois isto nem sempre acontece ao longo das entrevistas. A intenção aqui foi dar maior riqueza e robustez ao tratamento e às análises posteriores.

A exploração do material se deu pela escolha das unidades semânticas (Bardin, 2000) que foram as frases, os trechos de frases ou palavras-chaves, que constituíram as unidades semânticas, representando a essência do significado de cada pergunta. Para a exploração do material foram empregados os seguintes critérios: a) exclusão mútua, onde prevaleceu apenas a resposta de cada entrevistado, mais aderente à pergunta; b) homogeneidade, a adoção de um único critério de classificação; c) pertinência, entre as unidades semânticas e as perguntas; d) objetividade, em que as unidades semânticas representassem a essência das respostas; e) produtividade, as unidades semânticas em volume significativo para sintetizar as respostas. (Bardin, 2000).

A etapa do tratamento e dos dados foi realizada com o apoio de uma planilha, conforme segue: 1) 
distribuição das unidades semânticas referentes às respostas de cada entrevistado, pelas colunas da planilha, alinhadas à direita da primeira coluna que continha as perguntas; 2) síntese das unidades semânticas originadas das respostas de cada entrevistado, referentes às mesmas perguntas, por meio de leitura horizontal da planilha que resultaram nos temas, associados a cada objetivo específico; 3) síntese dos temas para resultar nas categorias, agora feita por meio de leitura vertical da planilha. Veja a configuração da planilha no Apêndice C. Com isso, as categorias acabaram elaboradas de maneira conectadas com os objetivos específicos de maneira a garantir a consistência nas análises subsequentes para se responder a questão de pesquisa, apresentadas no Quadro 1:

\begin{tabular}{|l|l|}
\hline \multicolumn{1}{|c|}{ OBJETIVOS ESPECÍfICOS } & CATEGORIAS CORRESPONDENTES \\
\hline \multirow{2}{*}{$\begin{array}{l}\text { 1. Entender os antecedentes da queda da } \\
\text { lucratividade do negócio. }\end{array}$} & Aumento da concorrência e dos custos dos produtos. \\
\cline { 2 - 2 } & Desatenção às necessidades dos clientes. \\
\hline \multirow{2}{*}{$\begin{array}{l}\text { 2. Descrever as estratégias envolvidas no } \\
\text { turnaround. }\end{array}$} & Redução de custos. \\
\cline { 2 - 2 } $\begin{array}{l}\text { 3. Caracterizar os recursos e capacidades } \\
\text { que se tornaram estratégicos no suporte das } \\
\text { estratégias do turnaround. }\end{array}$ & Revisão da estratégia de atendimento. \\
\cline { 2 - 2 } & Mudança de mindset e sinergia entre as áreas \\
\hline
\end{tabular}

Quadro 1 - Categorias resultantes do tratamento dos dados

Fonte: elaborado pelos autores.

\section{ANÁLISE DOS RESULTADOS}

A análise dos resultados teve como base a mesma estrutura das categorias elaboradas em relação a cada objetivo específico, apresentada no Quadro 1. Conforme já mencionado anteriormente, o Entrevistado 1 está referido como (E1), o Entrevistado 2 como (E2), e assim sucessivamente até o Entrevistado (E8).

\subsection{Aumento da Concorrência e dos Custos dos Produtos}

A resposta unânime entre os entrevistados como causa do declínio da lucratividade da empresa foi o aumento da concorrência em função do contexto econômico brasileiro de crescimento, fazendo com que os clientes tivessem novas opções de fornecedores, muitos deles oferecendo produtos com preços mais acessíveis. Em seguida estão alguns trechos dos principais depoimentos que ilustram essa observação.

[...] o ponto principal foi o aumento da competitividade, a entrada de novos concorrentes no Brasil durante esse período. [...] os concorrentes fizeram grandes investimentos [...] (E1)

[...] a entrada de concorrentes do nosso segmento em clientes [...] foi decisiva na diminuição da lucratividade [...] (E2)

[...] a entrada de novos concorrentes trabalhando com clientes estratégicos da empresa e ofertando produtos de custo reduzido. (E6)

Estes depoimentos atestam o aumento da concorrência como uma causa externa do declínio, e estão consistentes com as considerações de Bibeault (1999), Santos (2006), Slatter e Lovett (2009) e Torres et al. (2013). O aumento nos custos dos produtos também aparece nos depoimentos como importante causa do declínio da lucratividade da empresa, conforme pode ser observado a seguir.

[...] aumento do custo na cadeia de suprimentos, provocando também o aperto nas margens para se atingir as metas $[\ldots](\mathrm{E} 1)$

[...] houve um aumento da cadeia de suprimentos pela elevação de custos de algumas matérias primas. (E2)

[...] uma tendência de inflação em commodities, o custo Brasil aumentando bastante os preços de insumos básicos. (E5)

Assim, o aumento dos custos teve causas externas, em função de mudanças no mercado, e causas internas, devido a aumento dos custos da cadeia de suprimentos. Esses relatos corroboram as proposições de Weitzel e Jonsson (1989), Bibeault (1999), Santos (2006) e Slatter e Lovett (2009), que apontam como causa primária dessas causas internas e externas, a 
deficiência da gestão da empresa no controle dos custos internos e na identificação das mudanças exigidas pelo mercado, aspectos melhor detalhados na análise da categoria seguinte.

\subsection{Desatenção às Necessidades do Cliente}

Esta categoria surgiu da convergência dos depoimentos que indicaram a deficiência da gestão da empresa em antecipar as mudanças do mercado, em função da entrada de concorrentes e do aumento dos custos do produto, além de não observar que a relação custo-benefício para os clientes havia mudado. $\mathrm{O}$ foco estava na redução de custos dos produtos da empresa. Seguem alguns dos relatos onde é possível constatar essas deficiências.

[...] os resultados eram muito bons, talvez tenha ocorrido um relaxamento da parte da gestão. (E5)

[...] uma miopia da empresa por viver anos de grandes resultados, uma acomodação que fez perder o foco no cliente $[. .] ..(\mathrm{E} 1)$

[...] quando se percebeu já estava ocorrendo uma disputa bem acirrada com outros concorrentes. [...] houve demora para reagir adequadamente. (E8)

Os depoimentos corroboram as posições de Weitzel e Jonsson (1989), Bibeault (1999), Santos (2006) e Slatter e Lovett (2009), que apontam ser o declínio atribuído à deficiência da gestão, pela falha em antecipar, reconhecer, evitar, neutralizar, ou adaptar a estratégia para evitar ineficiências internas e ameaças do ambiente competitivo. Os relatos expõem claramente as deficiências da gestão da empresa em ajustar a estratégia às mudanças exigidas pelos clientes.

De acordo com os depoimentos a seguir, houve efetivamente mudanças das exigências dos clientes e demora na adequação das estratégias à nova dinâmica do mercado.

Mesmo com a oferta de produtos dos concorrentes com menor qualidade, os clientes focaram na redução de seus custos. [E2]

[...] é preciso reconhecer que a equipe comercial não estava com o foco adequado no cliente. (E3)

[...] no momento que o cliente valoriza a redução de custos e há maior agressividade por parte dos concorrentes, não poderia haver fragilidades na empresa. (E8)

[...] novos concorrentes ofertando produtos com custo reduzido, provocou o desinteresse do cliente pela oferta da empresa. (E6)
Esses depoimentos apontam a perda do diferencial competitivo no mercado, em função do não entendimento correto das necessidades e das mudanças de comportamento dos clientes. (Bibeault, 1999, Torres et al., 2013). A consequência disto foi uma oferta de produto aquém da expectativa do cliente, resultando em desvantagem da empresa em relação aos concorrentes.

Esses relatos demonstram convergência com o que defendem Peteraf e Barney (2003) e Zubac et al., (2010), uma vez que a empresa estava em desvantagem competitiva em relação aos concorrentes por não conhecer a correta percepção de valor do cliente, e dessa maneira não conseguir fornecer um produto com uma proposta de valor relevante para o cliente, do ponto de vista de preço e desempenho.

\subsection{Redução de Custos}

A redução de custos foi destacada pelos entrevistados como uma das estratégias mais relevantes adotadas pela empresa. Adiante estão os trechos de algumas das entrevistas, que confirmam a sua adoção.

Primeiro foram reduzidos os custos internos: de suprimentos, de matéria prima, custo de processo e o custo operacional. (E6)

Inicialmente foram revistos os processos internos, os processos produtivos [...] para a redução de custos de matérias primas, insumos, redução do número de matérias primas. (E4)

Foram várias iniciativas de redução de custos. Houve reformulação de produtos de baixa rentabilidade, melhoria de processos e da logística, [...] simplificação e otimização de matérias primas. (E1)

Assim, empresa adotou a redução de custos como primeira estratégia operacional, por meio de ações táticas indispensáveis em diferentes áreas da empresa, para permitir resultados de curto prazo visando a frear o declínio e recuperar a lucratividade (Hofer, 1980, Robbins \& Pearce, 1992, Bibeault, 1999).

\subsection{Revisão da Estratégia de Atendimento}

Esta categoria resultou da grande convergência das respostas dos entrevistados que apontaram a importância da revisão da estratégia de atendimento para focar em clientes que permitissem maior lucratividade, por intermédio de uma equipe comercial melhor preparada para identificar esses clientes, conforme segue. 
A grande mudança foi a reorganização do time comercial, com perfil profissional mais adequado [...] focado nos clientes prioritários. (E1)

[...] uma revisão da estratégia voltada para o atendimento aos clientes prioritários. (E3)

[...] buscou-se encontrar as oportunidades mais estratégicas que existiam no mercado [...]. (E6)

Conforme os relatos, a revisão da estratégia de atendimento esteve em conformidade com as estratégias de turnaround, pois permitiu melhor entendimento das necessidades do cliente, das oportunidades do mercado, por meio de uma equipe comercial mais adequada. (Hofer, 1980, Slatter \& Lovett, 2009). Com isso, foi possível identificar e focar o atendimento nos clientes mais lucrativos, que viabilizaram o turnaround. (Serra et al., 2009, Slatter \& Lovett, 2009).

Nos depoimentos que deram origem à esta categoria, vale destacar as particularidades da relação B2B. Conforme pode ser visto nos depoimentos a seguir, a questão do serviço agregado, suporte técnico e atendimento são particularidades importantes desse tipo de relação de negócios.

[...] foi proporcionado aos clientes um suporte técnico mais diferenciado em relação à concorrência. (E6)

[...] foram priorizadas ofertas de produtos e serviços focados em clientes e segmentos chaves da empresa (E4)

[...] o foco nos clientes para oferecer qualidade, alinhado a um suporte técnico robusto, como grande diferencial.. (E2)

A empresa se aproximou mais dos clientes prioritários por meio de sua equipe comercial com objetivo de entender o que esses clientes valorizavam, para fornecer serviços e suporte técnico agregado ao produto. (Christopher, 2003, Sinchi-Levi et al., Kaminsky \& Sinchi-Levi, 2007). Dessa maneira, os clientes prioritários puderam perceber benefícios agregados aos produtos, melhorando a sua expectativa de valor.

O destaque dos serviços agregados ao produto na relação B2B como estratégica para aproximar e melhorar a percepção do atendimento, resultou na atração dos clientes estratégicos.

\subsection{Equipe Comercial e Conhecimento Técnico - Recursos Intangíveis Estratégicos}

Esta categoria surgiu da convergência dos depoimentos em que se identificou o conhecimento técnico e a equipe comercial como sendo os recursos intangíveis nos quais a empresa se apoiou para a formulação da estratégia de turnaround. Esses recursos foram assumidos como valiosos pelos entrevistados, conforme revelado nos depoimentos a seguir:

A empresa buscou recursos comerciais e técnicos que pudessem recuperar a lucratividade e fazer com que o cliente visualizasse uma criação de valor. (E6)

[...] principalmente a expertise técnica nas reformulações para se ter um preço melhor [...] além de profissionais com muita experiência $[\ldots]$ (E1)

[...] o que fez muita diferença foi a equipe comercial, com a oferta adequada de produto. (E3)

[...] as alterações com o investimento na equipe comercial fizeram a diferença. (E8)

Os depoimentos demonstram que o recurso intangível "equipe comercial" foi valioso e fundamental para a estratégia de recuperação da lucratividade, pois possibilitou a identificação dos clientes prioritários, a aproximação com eles para entender sua percepção de valor e oferecer o produto e serviço agregados de maneira eficaz. Isso está em consonância com o que defendem Peteraf e Barney (2003) e com Zubac et al. (2010), no que diz respeito à importância do entendimento do valor para o cliente como base para identificação dos recursos internos que suportaram a estratégia.

Estando mais próxima e entendendo as necessidades dos clientes, a empresa se apoiou no recurso intangível, "conhecimento técnico", assumido também como valioso para desenvolver os produtos e o suporte técnico em conformidade com a percepção de valor destes clientes. Isso corrobora com os argumentos de Barney (1991) uma vez esse recurso permitiu que a empresa explorasse uma oportunidade do mercado, entregando aos clientes prioritários, maiores benefícios por um custo menor, resultando em beneficios financeiros para a empresa (Hofer, 1980, Hambrick \& Schecter, 1983).

A equipe comercial e o conhecimento técnico também foram assumidos como raros e difíceis de serem imitados, em função de serem únicos ou de alto custo de imitação, conforme os relatos adiante:

A expertise técnica da empresa era única, difícil de imitar, porque demandaria um investimento muito alto e os concorrentes não conseguiram reproduzila. (E4)

O conhecimento técnico que a empresa detinha foi um diferencial, realmente um recurso raro. (E2)

Havia profissionais muito capacitados na empresa que fizeram a diferença, pois conseguiram desenvolver produtos com 
preços mais competitivos e proporcionar um suporte técnico diferenciado em relação à concorrência. [...] também se tornou difícil de ser imitado. (E6)

A equipe comercial conforme com tal desempenho, teria levado muito tempo para ser imitada. (E3)

Esses relatos levam ao entendimento de que a equipe comercial e o conhecimento técnico se constituiram nos recursos raros e difíceis de serem imitados pelos concorrentes, o que lhe permitiu frear o declínio e recuperar a lucratividade, corroborando com o que defendem Wernerfelt (1984), Peteraf e Barney (2003), Barney e Clark (2007) e Barney e Hesterly (2011).

As narrativas a seguir indicam que a empresa também possuia sistemas internos que permitiram a sustentabilidade desses recursos na condição de valiosos, raros e dificeis de serem imitados:

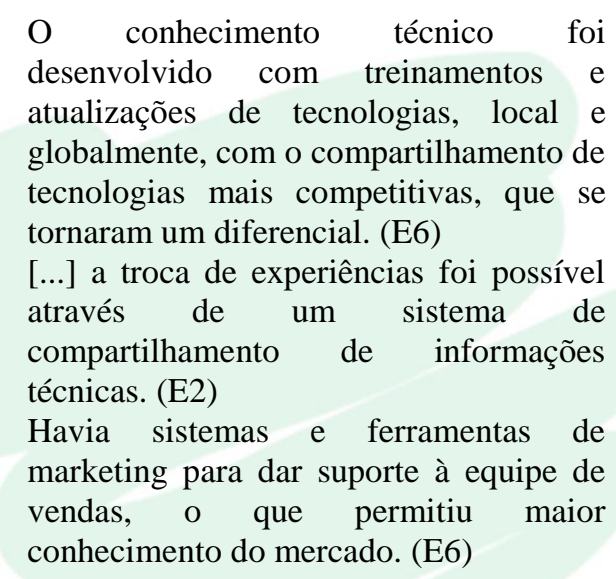

Esses sistemas e políticas internas permitiram que o conhecimento técnico e a equipe comercial pudessem ser atualizados e explorados de maneira eficiente pela empresa como um todo.

\subsection{Mudança de Mindset e Sinergia entre as Áreas - Capacidades Estratégicas}

A elaboração desta categoria ocorreu em função dos relatos indicarem a mudança de mindset e a sinergia entre as áreas internas da empresa, como as capacidades que deram sustentação às estratégias de turnaround e, dessa maneira, consideradas como estratégicas, conforme os relatos que seguem:

O ponto crucial foi a mudança de mindset interno, para atuar com um custo mais competitivo. [...] foi uma ação forte da gestão para fazer com que as pessoas atuassem como agentes de mudanças. (E1)

Foi necessário ajustar o nosso mindset [...] tendo se buscado um modelo mais competitivo de produtos e serviços para obter o mesmo sucesso já conseguido anteriormente.

Houve mais sinergia entre as diferentes áreas da empresa no sentido de melhorar o conhecimento do mercado e a criação de valor aos clientes. (E6)

Ocorreu a sinergia da equipe comercial com a equipe técnica. (E3)

[...] a melhor sinergia, uma maior integração entre as áreas que permitiu um case de sucesso de venda e lucratividade. (E4)

Os depoimentos destacados mostram que as capacidades foram desenvolvidas a partir de um objetivo específico e de uma equipe adequadamente liderada. Nesse sentido, a mudança de mindset promovida pela gestão da empresa fez com que a organização focasse em reduzir os custos e oferecesse um produto com serviço mais adequado à necessidade dos clientes prioritários, de maneira efetiva.

É importante observar a capacidade de sinergia entre as áreas como uma habilidade da empresa em combinar recursos de maneira complexa, para que fosse criado valor para os clientes prioritários por meio de produtos e serviços mais adequados. Isso coincide com as proposições de Grant (2001) e com os atributos defendidos por Barney (1991) indicando que essa sinergia pode ser considerada como valiosa.

Outros trechos das entrevistas revelam que a mudança de mindset e a sinergia entre as áreas são capacidades raras e difíceis de serem imitadas pelos concorrentes. Isso pode ser confirmado pelos depoimentos adiante:

Essa mudança de mindset seria difícil de ser imitada, pois passou a fazer parte do DNA da empresa. (E1)

Essa habilidade da liderança de definir novas metas, mais claras, e os objetivos mais específicos seria difícil ou custaria muito par ser imitada pelos concorrentes. (E2)

A sinergia entre a área comercial e técnica seria muito difícil e complexa de ser copiada porque ela envolve duas estruturas. (E3)

[...] foi difícil conseguir juntar grupos de pessoas e fazer com que trabalhassem de maneira sinergica. (E8)

As narrativas reconhecem que essas capacidades seriam raras, custosas e difíceis de serem imitadas pelos concorrentes e, por isto, permitiram à empresa reaver a sua vantagem competitiva.

Da mesma maneira que no caso dos recursos, a estrutura e sistemas internos permitiram o suporte 
organizacional para explorar eficazmente essas capacidades.

Existiam sistemas para garantir que essa sinergia acontecesse e continuasse suportando as estratégias de turnaround, tais como treinamentos e atualizações, e revisões estratégicas periódicas. (E4)

[...] isso também foi combinado com treinamento atualizado, seja técnico, seja comportamental. (E1)

É possível considerar que o sistema interno de desenvolvimento promoveu a interligação entre as áreas técnicas e de vendas, com base em treinamentos técnicos e comportamentais, em revisões estratégicas periódicas, garantindo que o mindset e a sinergia entre as áreas fossem explorados organizacionalmente. Isso fez com que essas capacidades continuassem suportando as estratégias da empresa. (Barney \& Clark, 2007). De acordo com o modelo VRIO, proposto por estes autores, as capacidades, mudança de mindset e sinergia entre as áreas, constituíram uma das fontes da retomada da vantagem competitiva.

Em resumo, os recursos, "equipe comercial e conhecimento técnico", assim como as capacidades, "mudança de mindset" e sinergia entre as áreas", podem ser caracterizados como estratégicos por terem possibilitado a freada do declínio e a recuperação da lucratividade da empresa.

\subsection{Aspecto Relevante Identificado}

Vale destacar um aspecto importante da teoria de turnaround que se confirmou neste estudo, qual seja, a mudança da liderança, conforme defendem
Schendel et al. (1976), Hofer (1980), Thiétart (1988) e Slatter e Lovett (2009). Os relatos a seguir são ilustrativos:

[...] precisava de uma readequação no time de liderança [...]. Foi feita a renovação importante na equipe de liderança, pessoas vieram do mercado, outras movimentadas de setores. Outras pessoas infelizmente tiveram que sair da empresa. A alteração na equipe de liderança permitiu também essa leitura mais atualizada dos clientes. (E8)

Primeiro, a demissão de algumas pessoas e a recontratação de pessoas mais adequadas para o perfil que a gente precisava. (E3)

As narrativas demonstram que a mudança na liderança da empresa foi o passo inicial necessário para que fosse feito um novo diagnóstico da situação da empresa em relação ao mercado, e com base nisso, novas estratégias puderam ser adotadas, o que corrobora com o que defendem Schendel et al. (1976), Hofer (1980), Thiétart (1988) e Slatter e Lovett (2009).

\subsection{Síntese dos Resultados}

O Quadro 2 mostra a associação entre as causas do declínio da lucratividade da empresa, as estratégias de turnaround que foram adotadas e os recursos e capacidades que suportaram estas estratégias. Nota-se a mudança da liderança como passo inicial e crítico para que o turnaround ocorresse, conforme detalhado no subitem 4.7 . 


\begin{tabular}{|c|c|c|c|}
\hline CAUSAS DO DECLÍNIO & \multicolumn{2}{|c|}{ ESTRATÉGIAS DE TURNAROUND } & RECURSOS E CAPACIDADES \\
\hline $\begin{array}{l}\text { Aumento da concorrência e } \\
\text { dos custos dos produtos } \\
\text { (Weitzel \& Jonsson, 1989, } \\
\text { Bibeault, 1999, Santos, 2006, } \\
\text { Slatter \& Lovett, 2009, Torres } \\
\text { et al.,2013). }\end{array}$ & \multirow{2}{*}{ 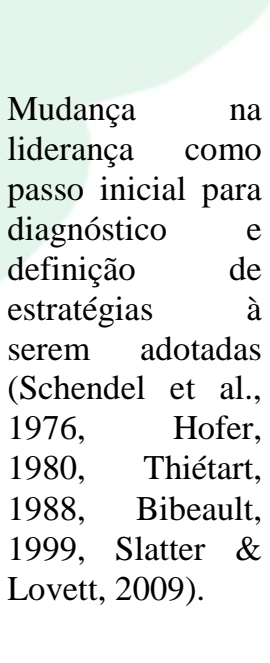 } & $\begin{array}{l}\text { Estratégia de redução } \\
\text { de custos (Hofer, 1980, } \\
\text { Robbins \& Pearce, } \\
\text { 1992, Bibeault, 1999). }\end{array}$ & $\begin{array}{l}\text { Equipe comercial e conhecimento } \\
\text { técnico - recursos intangíveis } \\
\text { estratégicos (Hofer, 1980, Hambrick } \\
\text { \& Schecter, 1983, Wernerfelt, 1984, } \\
\text { Barney, 1991, Peteraf \& Barney, } \\
\text { 2003, Barney \& Clark, 2007, Zubac } \\
\text { et al., 2010, Barney \& Hesterly, } \\
\text { 2011). }\end{array}$ \\
\hline 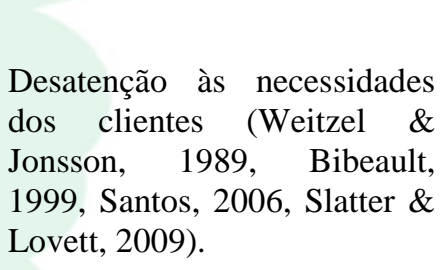 & & $\begin{array}{l}\text { Revisão da estratégia } \\
\text { de atendimento (Hofer, } \\
\text { 1980, Serra et al., } \\
\text { 2009, Slatter \& Lovett, } \\
\text { 2009). }\end{array}$ & $\begin{array}{l}\text { Mudança de mindset e sinergia entre } \\
\text { as áreas - capacidades estratégicas } \\
\text { (Barney, 1991, Grant, 2001, Barney } \\
\text { \& Clark, 2007). }\end{array}$ \\
\hline
\end{tabular}

Quadro 2 - Associação entre as causas do declínio, as estratégias de turnaround adotadas e os recursos e capacidades estratégicos.

Fonte: elaborado pelos autores.

\section{CONSIDERAÇÕES FINAIS}

Retomando a questão de pesquisa que buscou entender os recursos e capacidades da empresa que contribuíram para o turnaround, tendo em vista a volta da vantagem competitiva da empresa, é possível afirmar que os recursos, equipe comercial e conhecimento técnico, e as capacidades, mudança de mindset e sinergia entre as áreas da empresa, foram fundamentais para as estratégias que permitiram à empresa recuperar a sua lucratividade.

A dificuldade para perceber as mudanças do mercado ocasionadas pelo aumento da concorrência e dos custos dos produtos, e o desconhecimento das necessidades dos clientes, se destacaram como as causas do declínio, ambas atribuídas à deficiência da gestão da empresa em antever e adaptar as estratégias as mudanças do cenário externo. Diante disso, as mudanças na equipe de liderança da empresa marcaram o início do turnaround, por meio de uma revisão que definiu as estratégias que possibilitaram a retomada da vantagem competitiva.

A estratégia de redução de custos, por intermédio de revisões de processos internos diversos, foi o primeiro passo que da recuperação de parte da lucratividade no curto prazo, com ações operacionais. Em paralelo, a revisão da estratégia de atendimento resultou na criação de uma equipe comercial mais focada em identificar os clientes que possibilitavam maior retorno, definidos como prioritários.
Essa estratégia de atendimento foi bem sucedida pelo fato da empresa atuar no segmento em uma relação B2B, em função da aproximação do cliente que permitiu captar a percepção de valor dos clientes prioritários, e com isso agregar o suporte técnico que esses clientes valorizavam.

A equipe comercial e o conhecimento técnico foram essenciais por terem suportado especialmente as estratégias de atendimento que foram importantes para o retorno de clientes anteriormente perdidos para a concorrência. $\mathrm{O}$ conhecimento técnico foi decisivo na reformulação de produtos com a mesma qualidade e com menores custos, além do serviço que foi agregado ao produto impactando positivamente a satisfação dos clientes. A equipe comercial focou os clientes prioritários, buscou entender com mais clareza as suas necessidades, tendo ajustado com a equipe técnica a oferta de valor mais adequada àqueles clientes.

Esses recursos, tidos como estratégicos, não teriam sido assim considerados se não fosse a capacidade, também estratégica, de mudança de mindset e sinergia entre as áreas internas da empresa. A introdução de uma nova equipe de liderança, logo no início do processo, facilitou essa mudança de mindset, ou seja, fez com que a organização com um todo focasse nos objetivos de reduzir os custos internos e de atender as necessidades dos clientes prioritários. Isso facilitou a obtenção de sinergia entre as áreas comercial, marketing e técnica, por ter sido um meio eficiente para a obtenção mais rápida de resultados. 
Importa ressaltar que a mudança da liderança foi um fator de grande relevância para que o processo do turnaround acontecesse, por ter sido uma decisão da empresa que se mostrou adequada a esta finalidade. Essa foi uma importante descoberta adicional do estudo.

O método qualitativo adotado, de caráter descritivo, foi produtivo na coleta, tratamento e análise dos dados que resultaram em informações robustas $\mathrm{e}$ precisas para responder à questão de pesquisa proposta no estudo.

A fundamentação na VBR possibilitou a análise do turnaround de maneira objetiva e eficiente, tendo facilitado a construção do modelo da pesquisa e a sua realização. Facilitou também a construção do instrumento para a condução das entrevistas, possibilitando aos entrevistados entenderem os conceitos de recursos e capacidades e, consequentemente, darem as respostas adequadas aos objetivos da pesquisa. Além disso, mostrou-se aplicável ao estudo de situações de mudanças repentinas no cenário externo, como neste estudo. Os resultados obtidos são esperados contribuir para a ampliação do conhecimento sobre esta teoria por ter suportado efetivamente o entendimento do fenômeno turnaround.

Espera-se também que a empresa objeto do estudo possa se apropriar dos vários aspectos revelados no estudo, especialmente quanto à gestão dos recursos e das capacidades que se mostraram como estratégico, tendo em vista manter a sua vantagem competitiva, depois de tê-la perdido.

Não obstante ter sido um estudo de caso, sem a intenção de generalização, os passos e procedimentos metodológicos adotados podem ser seguidos por outras empresas que se vejam na situação de realizarem um turnaround.

Com relação às limitações da pesquisa, além daqueles naturais de um estudo de caso, há que se ressaltar que as entrevistas ocorreram em momento de bonança. Com isso, muitos aspectos podem ter sido minimizados ou mesmo considerados pouco relevantes, tendo em vista que um evento dessa natureza deve ter trazido muitos transtornos e conflitos que os entrevistados tenham evitado comentar. Também se destaca como limitação o fato de não ter sido possível se conhecer a opinião de clientes que deixaram a empresa pelos concorrentes, tendo em vista diferentes ofertas de valor dos concorrentes. Outra limitação tem a ver com a exigência de anonimato da empresa, que dificultou uma análise em relação a outras empresas do segmento, especialmente em relação aos concorrentes imediatos que provocaram perdas à sua lucratividade e à vantagem competitiva.

Recomendam-se futuros estudos que explorem o comportamento de recursos e capacidades estratégicas em situação de turnaround em negócios que envolvam relações B2C, incorporando a visão dos clientes que abandonaram e depois voltaram a comprar da empresa.

\section{REFERÊNCIAS}

Bardin, L. (2000). Análise de Conteúdo. Lisboa: Edições 70.

Barney, J. B. (1991). Firm resources and sustained competitive advantage. Journal of Management, 17, 99-121.

Barney, J. B. \& Clark, D. N. (2007). Resource-based theory: creating and sustaining competitive advantage. New York: Oxford University Press.

Barney, J. B. \& Hesterly, W. S. (2011). Administração estratégica e vantagem competitiva. São Paulo: Pearson Prentice Hall.

Bibeault, D. (1999). Corporate turnaround: how managers turn losers into winners. Washington: Beards Books. Originalmente publicado em New York: McGraw-Hill, 1982.

Bowman, C. \& Ambrosini, V. (2000). Value Creation Versus Value Capture: Towards a Coherent Definition of Value in Strategy. British Journal of Management, 11, 1-15.

Carvalho, K. L. (2013). Uma proposta para o diagnóstico do declínio organizacional. Tese de Doutorado, Escola Politécnica, Universidade de São Paulo, São Paulo. doi:10.11606/T.3.2013.tde07062014-121156. Recuperado de www.teses.usp.br; em 24/06/2017.

Christopher, M. A Logística do Marketing ( $5^{\mathrm{a}}$ ed.). General Salgado, SP: Ed. Futura, 2003.

Collis, J. \& Hussey, R. (2005). Pesquisa em Administração (2 ${ }^{\mathrm{a}}$ ed.). Porto Alegre: Bookman.

Creswell, J. W. (2007). Projeto de pesquisa: métodos qualitativo, quantitativo e misto ( $2^{\mathrm{a}}$ ed.). Porto Alegre: Artmed.

Flick, U. (2004). Uma introdução à pesquisa qualitativa ( $2^{\mathrm{a}}$ ed.). Porto Alegre: Bookman.

Grant, R. M. (1991). The resource-based theory of competitive advantage: implications for strategy formulation. California Management Review, 33 (3), 114-135.

Hall, R. (1992). The strategic analysis of intangible resources. Strategic Management Journal, 13 (2).

Hambrick, D. C. \& Schecter, S. M. (1983). Turnaround strategies for mature industrial-product business 
units. Academy of management Journal, 26 (2), 231-248.

Helfat, C. E. \& Peteraf, M. A. (2003). The dynamic resource-based view: Capability lifecycles. Strategic Management Journal, 24(10), 997-1010.

Hofer, C. W. (1980). Turnaround strategies. Journal of Business Strategy, (1), 19-31.

Kretzer, J. \& Menezes, E. A. (2006). A Importância da Visão Baseada em Recursos na

Explicação da Vantagem Competitiva. Revista de Administração Mackenzie, 4 (4), 63-87.

Kristandl, G. \& Bontis, N. (2007). Constructing a definition for intangibles using the resource based view of the firm. Management Decision, 45 (9).

Peteraf, M. A. \& Barney, J. B. (2003). Unraveling the resource-based tangle. Managerial and Decision Economics, 24, 309-323.

Pinto, R. F., Guerrazzi, L. A. C., Serra, B. P. C. \& Kniess, C T. (2016). A pesquisa em administração estratégica: um estudo bibliométrico em periódicos internacionais de estratégia no período de 2008 a 2013. Revista Ibero-Americana de Estratégia, 15 (2), 22-37.

Purves, N., Niblock, S., \& Sloan, K. (2016). Are organizations destined to fail? Management Research Review, 39(1), 62-81.

Robbins, D. K. \& Pearce, J. A. (1992). Turnaround: Retrenchment and recovery. Strategic Management Journal, 13 (4), 287-309.

Santos, P. J. M. D. (2006). Declínio organizacional e estratégias de recuperação nas pequenas e médias empresas: uma abordagem holística. Tese de doutorado, Universidade Aberta, Lisboa, Portugal.

Schendel, D., Patton, G. \& Riggs, J. (1976). Corporate turnaround strategies: a study of profit decline and recovery. Journal of General Management, 3 (3), Spring, 3-11.
Serra, F., Ferreira, M. \& Contrigiane, E. (2009). Turbulência nos anos 1990: o" turnaround" da Bunge. Revista Portuguesa e Brasileira de Gestão, 8 (1), 76-88.

Sinchi-Levi, D., Kaminsky, P. \& Sinchi-Levi, E. (2007). Cadeia de Suprimentos: Projeto e Gestão. Porto Alegre: Artmed.

Sirmon, D. G., Hitt, M. A. \& Ireland, R. D. (2007). Managing firm resources in dynamic environments to create value: Looking inside the black box. Academy of Management Review, 32 (1), 273292.

Slatter, S. \& Lovett, D. (2009). Como recuperar uma empresa: a gestão da recuperação do valor e da performance. São Paulo: Atlas.

Torres, A., Menezes, E., Serra, F., \& Ferreira, M. P. (2008). O declínio das grandes empresas brasileiras. Globadvantage Working Paper Series, 26. Portugal: IC-Online. Disponível em: < http://hdl.handle.net/10400.8/368. Acesso em: 30/06/2017.

Torres, A. P., Serra, F. R. Almeida, M. R. \& Ferreira, M. P. (2013). O declínio de uma empresa brasileira de grande porte: O caso Gradiente. Revista de Administração e Contabilidade da Unisinos BASE, 10 (3), 273-292.

Weitzel, W. \& Jonsson, E. (1989). Decline in organizations: a literature integration and extension. Administrative Science Quarterly, 34 (1), 91-109.

Wernerfelt, B. (1984). A resource-based view of the firm. Strategic Management Journal, 5 (2), 171180.

Yin, R. (2005). Estudo de caso: planejamento $e$ métodos. $3^{\mathrm{a}}$ ed. Porto Alegre: Bookman.

Zubac, A., Hubbard G. \& Johnson W. L. (, 2010). The RBV and value creation: a managerial perspective. European Business Review, 22 (5), 515-538. 


\section{APÊNDICE A - Roteiro de entrevistas}

1. Quais foram os fatores que causaram a queda de lucratividade da empresa em 2009 ?

2. Especificamente em relação ao produto, que fatores provocaram o desinteresse dos clientes ou fizeram com que eles optassem pelos dos concorrentes?

3. Quais foram as principais estratégias adotadas para recuperação da lucratividade? Quais no

nível operacional e quais no nível estratégico?

4. Como resultado das estratégias de recuperação, que aspectos melhoraram o produto provocando interesse do cliente em relação aos dos concorrentes?

5. Quais foram os principais recursos e capacidades da empresa que viabilizaram a criação de

valor superior e, consequentemente, suportaram as estratégias de recuperação da lucratividade? Considere recurso como ativos tangíveis (exemplos: equipamentos, estrutura física, etc.) e intangíveis (exemplos: marca, conhecimento, trabalho em equipe, et.) utilizados para formular estratégias e capacidades, a habilidade de combinar recursos para obter resultados produtivos.

6. Esses recurso e capacidades apontados são raro ao ponto de serem controlados pela empresa ou por um número pequeno de concorrentes?

7. Esses recursos e capacidades são difíceis ou custoso de ser imitados ou reproduzidos pelos concorrentes?

8. Que estrutura e sistemas organizacionais permitiram que os recursos e capacidades, valiosos, raros e difíceis de serem imitados dessem suporte à recuperação? Como a empresa garantiu que continuassem a ser explorados pela organização evitando que eles deixassem de contribuir para geração de valor para o cliente?

APÊNDICE B - Matriz de amarração utilizada na elaboração do roteiro de perguntas

Questão de pesquisa:

Objetivo geral:

\begin{tabular}{|c|l|l|}
\hline $\begin{array}{c}\text { Objetivos } \\
\text { específicos }\end{array}$ & Referencial Teórico & Perguntas roteiro entrevistas \\
\hline & & \\
\hline & & \\
\hline & & \\
\hline
\end{tabular}

Fonte: Elaborada pelos autores.

APÊNDICE C - Planilha de categorização dos dados qualitativos

Questão de pesquisa:

Objetivo geral:

\begin{tabular}{|c|c|c|c|c|c|c|c|}
\hline $\begin{array}{l}\text { Objetivos } \\
\text { específicos }\end{array}$ & Perguntas & $\begin{array}{c}\text { Entrevistado } \\
1\end{array}$ & $\begin{array}{c}\text { Entrevistado } \\
2\end{array}$ & $\begin{array}{c}\text { Entrevistado } \\
\text { n }\end{array}$ & $\begin{array}{l}\text { Síntese das } \\
\text { unidades } \\
\text { semânticas }\end{array}$ & Temas & Categorias \\
\hline & & & & & & & \\
\hline & & & & & & & \\
\hline & & & & & & & \\
\hline & & & & & & & \\
\hline & & & & & & & \\
\hline & & & & & & & \\
\hline & & & & & & & \\
\hline & & & & & & & \\
\hline & & & & & & & \\
\hline & & & & & & & \\
\hline
\end{tabular}

Fonte: Elaborado pelos autores. 